\title{
Gérard Defois, Le pouvoir et la grâce : le prêtre, du Concile de Trente à Vatican II
}

Paris, Éditions du Cerf, coll. « Théologies », 2013, 400 p.

\section{Alain Rauwel}

\section{(2) OpenEdition}

\section{Journals}

Édition électronique

URL : http://journals.openedition.org/assr/25454

DOI : $10.4000 /$ assr. 25454

ISSN : $1777-5825$

Éditeur

Éditions de l'EHESS

Édition imprimée

Date de publication : 30 décembre 2013

Pagination : 179

ISSN : 0335-5985

Référence électronique

Alain Rauwel, «Gérard Defois, Le pouvoir et la grâce : le prêtre, du Concile de Trente à Vatican II », Archives de sciences sociales des religions [En ligne], 164 | 2013, mis en ligne le 20 février 2014, consulté le 21 septembre 2020. URL : http://journals.openedition.org/assr/25454 ; DOI : https:// doi.org/10.4000/assr.25454

Ce document a été généré automatiquement le 21 septembre 2020.

(c) Archives de sciences sociales des religions 
Gérard Defois, Le pouvoir et la grâce : le prêtre, du Concile de Trente à Vatican II

Paris, Éditions du Cerf, coll. « Théologies », 2013, 400 p.

Alain Rauwel

RÉFÉRENCE

Gérard Defois, Le pouvoir et la grâce : le prêtre, du Concile de Trente à Vatican II, Paris, Éditions du Cerf, coll. « Théologies », 2013, 400 p. 
1 Il est difficile de déterminer la nature exacte de l'essai que consacre à la figure sacerdotale dans la modernité Gérard Defois, archevêque émérite de Lille. Le recours à des textes relevant davantage de la spiritualité que de la doctrine ne permet pas d'y voir un traité théologique systématique. Le regard lucide, mais quelque peu impressionniste porté sur l'insertion sociale du prêtre empêche d'y trouver à proprement parler une sociologie. Et le choix de privilégier des moments considérés comme particulièrement emblématiques ne donne pas à l'historien le continuum qu'il attendrait. Ce pas de côté par rapport aux méthodes disciplinaires n'enlève cependant rien à l'intérêt que peut susciter l'ample panorama de Gérard Defois. Chapitre après chapitre, l'auteur retient quelques figures ou événements

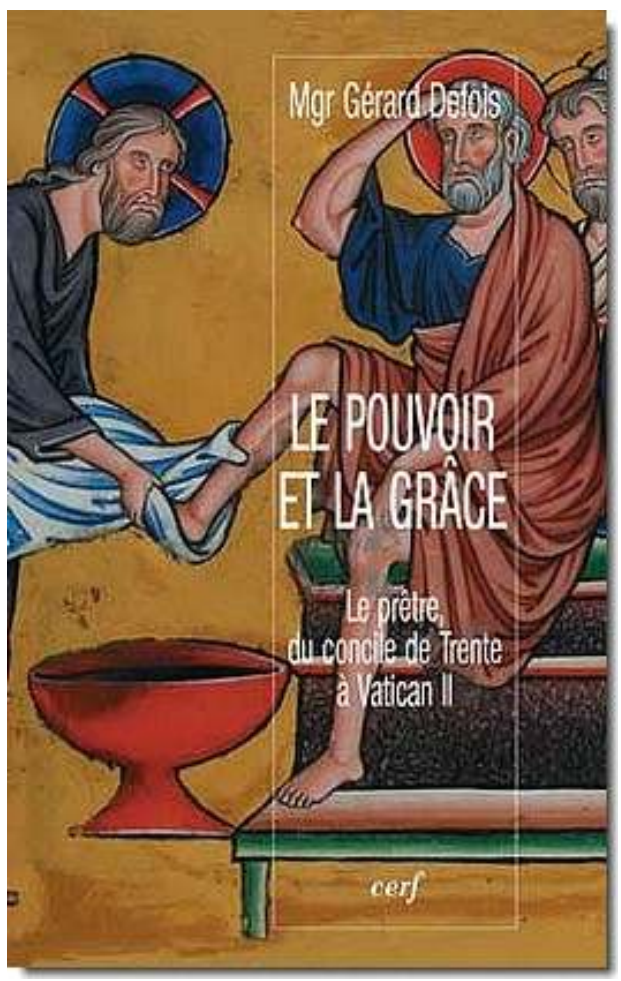
ayant donné lieu à un texte reconnu comme « classique » qu'il analyse en détail. Le choc initial est celui du nouveau discours sur le sacerdoce produit par Luther, auquel répondent les élaborations tridentines, reprises et «traduites" par François de Sales. Viennent ensuite les grands noms de l'École française de spiritualité, Bérulle, Jean Eudes, Vincent de Paul, Ollier, décisifs non seulement en leur siècle, mais sur la longue durée, par le biais des séminaires souvent tenus par les Sulpiciens ou les Lazaristes. Le temps des Lumières conduit à relire des auteurs bien oubliés, comme Bergier. De même, l'étude du traumatisme révolutionnaire suscite un regard sympathique sur les décisions des conciles nationaux de l'Église constitutionnelle, vite ensevelies sous le système nouveau du Concordat, mais que Gérard Defois met en relation, de façon très pertinente et suggestive, avec les discours des congrès sacerdotaux de la décennie 1890-1900. Le xIX siècle ramène vers des modèles mieux connus, Jean-Marie Vianney et Antoine Chevrier, mais aussi vers des textes plus originaux comme le factum De l'état du clergé en France des frères Allignol. Après 1914, on ne voit pas sans sourire l'auteur visiter pieusement la galerie des grands ancêtres de la pastorale moderne : l'abbé Guérin de la JOC, les abbés Godin et Daniel de France pays de mission, le cardinal Suhard de la pastorale de 1949... Et comme on s'en doute, le chapitre final, fort de plus de cinquante pages, porte sur le second concile du Vatican comme " point lumineux » et aboutissement du long itinéraire précédemment parcouru.

2 On l'aura noté : le corpus rassemblé est exclusivement français. C'est évidemment une limite. Sans aller jusqu'aux mondes missionnaires, un minimum de comparaison avec les clergés pléthoriques des Chrétientés du sud, les clergés minoritaires comme celui de l'Angleterre victorienne, la diversité de l'Europe germanique aurait nuancé un certain nombre de diagnostics et ouvert des perspectives que le cadre national bouche d'emblée. De même, s'il est parfaitement légitime de considérer que les Réformes 
marquent une rupture instauratrice, on eût aimé que Gérard Defois fit plus souvent référence aux institutions et aux théologies antérieures, sans lesquelles bien des discours ne se comprennent pas. Il est évident qu'en Chrétienté, toute pensée de la hiérarchie ne peut que se nourrir du dionysisme - mais cette juste observation souffre de n'être appuyée que... par une allocution de Benoît XVI! Une sentence comme celle de Bérulle selon qui le prêtre est "comme une personne publique tenant le rôle de Dieu " ne fait sens que rapportée aux réflexions scolastiques sur la dialectique du célébrant agissant à l'autel à la fois comme "persona privata " quand il implore miséricorde pour lui et comme "persona publica » quand il intercède au nom de toute l'Église. De même, ramener la formule "sacerdos alter Christus" à la seule École française conduit à manquer le chantier médiéval où s'affine tout le répertoire de références et d'images dans lequel les siècles suivants puiseront à pleines mains. Quant à l'omniprésence du rapprochement entre le prêtre et la Vierge, l'un engendrant le Christ dans les âmes comme l'autre l'a engendré en son sein, on pourra juger que l'ouvrage ne lui fait pas assez justice, malgré les intuitions toujours fécondes de la grande thèse de René Laurentin Maria, Ecclesia, sacerdotium. Ces timidités sont la contrepartie de la démarche rigoureuse à laquelle s'est astreint l'auteur : en avançant méthodiquement, il s'est interdit des excursions qui eussent sans doute été profitables à son lecteur.

Pour autant, il est des points particulièrement bien vus. Gérard Defois souligne le rôle fondamental de la sacramentalité de l'épiscopat, très atténuée après le XIII ${ }^{\mathrm{e}}$ siècle : c'est son absence dans l'ecclésiologie qui a réduit les évêques à n'être que des administrateurs, des "préfets violets ", dans la mesure où ils étaient (sont ?) seulement les supérieurs hiérarchiques de leurs prêtres, sacramentellement aussi compétents qu'eux. À l'inverse, le retour en force de la sacramentalité à Vatican II conduit à penser tout le système clérical à partir de l'évêque docteur et liturge - ce qui n'entraîne d'ailleurs pas nécessairement la revalorisation du presbytérat espérée par beaucoup dans les années 1960 et explique la postérité ambiguë d'un décret sur les prêtres tardivement approuvé et jamais considéré comme un document phare. La même incertitude est à l'œuvre dans la revendication récurrente d'un retour aux fondamentaux de la tradition sacerdotale contre les errements supposés des novateurs; Gérard Defois refuse à très juste titre d'y repérer un véritable antimodernisme, puisque le critère, au vrai, n'est pas tant l'alignement objectif sur un modèle institué que le choix subjectif d'une préférence stylistique : une manifestation, donc, d'une primauté du moi aussi «moderne » que possible. Le pouvoir et la grâce donne encore à lire la longue survie de motifs spirituels et moraux: «le prêtre doit être comme le Dieu de l'Église ", affirme abruptement Olier; il "continue l'œuvre de la rédemption sur la terre ", dit encore le curé d'Ars; il est « un sauveur, un autre JésusChrist ", revendique toujours l'un des "progressistes» du congrès de Reims en 1896. Trois moments, trois milieux aussi différents que possible, mais un discours substantiellement identique. Le postulat de Gérard Defois trouve ici sa justification: l'analyse patiente de textes de natures diverses, choisis pour leur représentativité, met en lumière des complexités qu'une étude de la condition, du statut ou de l'activité n'aurait sans doute pas si bien révélées. Pour l'originalité de son projet, l'intérêt des références retenues, la lecture nuancée qui en est proposée, la résistance méritoire à la tentation du dogmatisme abrupt, la synthèse de l'archevêque émérite de Lille mérite à coup sûr de retenir l'attention. 